\title{
Optimism, Gratitude and Emotional Intelligence as Correlates of Self-Confidence of Early Adults
}

\author{
Priti Sharma ${ }^{1}$, Sanjay Kumar ${ }^{2}$

\section{ABSTRACT}

The aim of the present study was to examine the emotional intelligence, gratitude and optimism as correlates of self-confidence of male and female early adults. Sample was consisted of 200 male and female post graduate students of age range 21 to 27 years. These subjects were taken from C.C.S. University Campus and degree colleges of Meerut city by quota random sampling. The measurement of variables under study was done through standardized tools individually. The tabulated data was analyzed by Pearson's correlation and regression analysis using step wise method. Obtained results were showing a negative significant correlation between selfconfidence and optimism and emotional intelligence at.01 level of significance in total subject and gender groups. The regression analysis has indicated that optimism and emotional intelligence were predictive variables for self-confidence of early adult subjects.

Keywords: Gender, Optimism, gratitude, Emotional Intelligence, Self-confidence.

Self-confidence is that one has on one self, one's knowledge and one's abilities. In many cases it is observed to be much more important variable than many other abilities and traits. Therefore, it is said that pure self-confidence is necessary for success, because in challenging circumstances, it integrates the power to attain goal. It also helps the bearer to progress, develop and achieve in adverse circumstances. Some time it becomes the decision maker of success for a person who might have average abilities and knowledge. This means that success becomes easy even in an adverse condition when self confidence coordinates the processes of mind. Cognitive psychologist suggested that it increases the thinking abilities, interest, courage, enthusiasm and faith in one self, which make a person to perform successfully at need. Lam and Brown (2004) examined that a person with high self-confidence evaluates the feedback at hand successfully which increases the possibility of success for person. This means that correct evaluation of coming stimuli increase the motivation to organize ones abilities to plan and execute for success.

${ }^{1}$ Research Scholar (PhD), R.G.P.G. Collage, Meerut

${ }^{2}$ Assistant Professor, Department of Psychology, Ch. Charan Singh University Campus Meerut

(C) 2015 I P Sharma, S Kumar; licensee IJIP. This is an Open Access Research distributed under the terms of the Creative Commons Attribution License (http://creativecommons.org/licenses/by/2.0), which permits unrestricted use, distribution, and reproduction in any Medium, provided the original work is properly cited. 


\section{Optimism, Gratitude and Emotional Intelligence as Correlates of Self-Confidence of Early Adults}

The empirical studies revealed that self-confidence is associated with some perceived characteristic of a person. So during adequate self confidence, person perceives himself to be socially competent, emotionally mature, intellectually adequate, successfully satisfied, optimistic, independent, forward moving, fairly assertive and having leadership qualities. Jones (2001) said that self is the knowledge that you can do something and do it well. Cox (2001) told that self-confidence is a belief in our self and our abilities. It is a mental attitude of transiting or relaying on one's own self. It is a tool that can help us manage our fears, tackle life's challenges with more certainty and maintain a positive mental attitude (Brown (2004). The review of literature reveals that people with high self-confidence are generally happier and more satisfied with their lives with good mental health and positive self-esteem. Empirical studies revealed that self-confidence is correlated with some personality traits with positive attitude towards one's self confidence (Cheng \& Furnham, 2002)

Studies suggested that parental behavior, peer group and teaching to the child play a vital role in the development of self-confidence, because parents make their children feel loved and accepted despite their imperfections will most likely encourage self-confidence. The approvals of socially appropriate behavior by parents influence self confidence significantly in both male and female adolescents (Thomas \& Miller 2001). When encouraged subjects display their qualities and abilities to parents, teachers and relative and get appropriate appreciation also help them improve their self-confidence by favorable encouraging from the environment. Similarly experiencing praise from new people, situation, place and outcomes provide positive feedback to internalized or brought self-confidence into the person. Thus, behavior and self-esteem are component of self confidence and positive experiential outcomes.

\section{OPTIMISM, GRATITUDE AND EMOTIONAL INTELLIGENCE}

The self confidence is also suggested as a type of traits affected by some cognitive, emotional, experiential and social factors. The investigator was interested to find out relationship of self confidence with some positive traits of personality more often used at work place and in performance situations. There is long list of human traits which is directly or indirectly related to self-confidence, but the present study considers optimism, gratitude and emotional intelligence as influencing factors of self-confidence. Optimism is the foundation on which all selfconfidence is built. The positive thinking, optimism and self-confidence are tied together tightly. The optimism functions as a guide to self-confidence. A self confident person perceives himself to be socially competent, emotionally mature, successful and optimistic as well (Goel \& Aggarwal, 2012). Gratitude or thankfulness is a positive emotion or attitude in acknowledgement of a benefit that one has received or will receive. Gratitude is also a human strength that is necessary for self confidence (Emmons \& Crumpler, 2000). The Emotional Intelligence is also related to self-confidence (Rajput, 2013) because having high selfconfidence tend to create a habitual state of behavior in a particular way in which emotional factors play a vital role. So the three variables are related to self confidence rationally. 


\section{METHOD}

\section{Objectives}

1. To study the optimism, gratitude and Emotional Intelligence as correlates of selfconfidence of male and female early adult_subjects.

2. To study if optimism, gratitude and Emotional Intelligence function as predictor of selfconfidence of male and female subjects.

\section{Sample}

The sample for the study was consisted of a total of 200 college and university male and female student subjects of age group 21 to 27 years. These subjects were taken from C.C.S. University Campus and its affiliated colleges of Meerut. The subjects were belonging to medium economic status families. The total subjects were further consisted of 100 male and 100 female subjects.

\section{Tools}

Following tools was used to measure the variable under study:

1. Self-confidence Inventory developed by Dr. Rekha Agnihotry (1987). The Scale has 56 items in it. The obtained reliability by Split-half method was very high $(\mathrm{N}=362$, Reliability=.95). The Validity coefficient were determined for each item through biserial correlation method and only those items were retained which were showing .25 or above biserial correlation with the total score. The validity coefficient obtained was .82 which is significant beyond .01 level

2. Optimism scale or LOT was developed by Schier, Corver and Bridges (1994). The test was a 10 item scale which was developed to assess individual difference in generalized optimism versus pessimism. This measure has been used in a good deal of research on the behavioral, affective and health consequences of the optimism/pessimism dimension. The items 2, 5, 6 and 8 were filler items only and added later on and they are not scored as part of the revised scale. Reliability of the test was internal consistency Cronbach's alpha $=0.71$ and stability over a 3- months period $(\mathrm{r}=0.66)$. The scale exhibited good convergent validity with single-item optimism scale ( $\mathrm{r}=0.73)$.

3. The gratitude questionnaire was developed by McCullough, Emmons \& Tsang (2002). The gratitude questionnaire has 6 items in it. Psychometrics of the original gratitude questionnaire was satisfactory. Other studies has also found that the instrument is reliable \& valid (e.g.), Giacalone et. al. 2005 ; Kashdan et al. 2006; Mc Collough et al. 2004; watkins et al. 2006.)

4. Emotional Intelligence Scale was developed by Anukool Hyde, Sanjot and Upinder (2000). The Scale has 34 items in it. The The split- half reliability coefficient was found to be 0.88. Besides face validity, as well items were related to the variable under focus, the scale has high content validity. In order to find out the validity the reliability index was calculated, which indicated high validity on account of being 0.93 . 


\section{Procedure}

The data was collected individually from each subject after developing healthy rapport with the subject. The experimental properties of sample were tried to be maintained while selecting the sample to attain the high internal validity of results.

\section{RESULTS}

The systematically tabulated data was evaluated by Pearson Correlation and multiple regression analysis using stepwise method through SPSS, 0.16 versions. The descriptive analysis of obtained results is given as follows.

\section{Co-relational Analysis of Total Subjects}

Table 1:- Showing Coefficient of Correlation between Self-confidence and Optimism, Gratitude and Emotional Intelligence of total subjects (N-200)

\begin{tabular}{|l|l|l|l|}
\hline Variables & Optimism & Gratitude & $\begin{array}{l}\text { Emotional } \\
\text { Intelligence }\end{array}$ \\
\hline Self-Confidence & $-0.24 * *$ & -0.13 & $-0.22 * *$ \\
\hline
\end{tabular}

The study of Table-1 showing that self-confidence was found significantly and negatively correlated with optimism $(\mathrm{r}=-.24 ; \mathrm{p}<.01)$ and Emotional Intelligence $(\mathrm{r}=0.22 ; \mathrm{p}<.01)$ at .01 level of significant. This means that those subjects who have high optimism and emotional intelligence would have low/ not need self-confidence among college going early adults. No significant correlation was obtained between self confidence and gratitude $(r=-0.13 ; \mathrm{p}>.05)$ among college going early adults.

Comparison of Coefficient of correlation of Male and Female Subjects

Table 2 Showing Comparison of Coefficient of Correlations between Self Confidence and Optimism, Gratitude and Emotional Intelligence of Male and Female Subjects

\begin{tabular}{|l|l|l|l|l|l|l|}
\hline \multirow{2}{*}{$\begin{array}{l}\text { Self } \\
\text { Confidence }\end{array}$} & \multicolumn{2}{|l|}{ Optimism } & \multicolumn{2}{l|}{ Gratitude } & \multicolumn{2}{l|}{$\begin{array}{l}\text { Emotional } \\
\text { Intelligence }\end{array}$} \\
\cline { 2 - 7 } & Male & Female & Male & Female & Male & Female \\
\cline { 2 - 7 } & $-0.23^{*}$ & $-0.24^{*}$ & -0.08 & -0.18 & $-0.23^{*}$ & -0.18 \\
\hline
\end{tabular}

It was obtained from the Table-2 that the correlation between self-confidence and optimism was found negatively and significantly correlated with optimism in both male $\left(r=-23^{*} ; \mathrm{p}<.05\right)$ and female $\left(\mathrm{r}=-.24^{*} ; \mathrm{p}<.05\right)$ subjects at .05 level of significance. Moreover, the self confidence was found significantly and negatively correlated with gratitude in male subjects $\left(\mathrm{r}=-.23^{*} ; \mathrm{p}<.05\right)$ at .05 level of significance but not in female subjects ( $r=-.18 ; \mathrm{p}>.05)$. Further the Table-2 indicated an insignificant correlation between self-confidence and emotional intelligence in both male ( $\mathrm{r}=-$ $.08 ; \mathrm{p}>.05)$ and female $\left(\mathrm{r}=.18^{*} ; \mathrm{p}<.05\right)$ early adult subjects. This revealed that optimism and gratitude co-vary with self confidence similarly in male and female subjects but emotional intelligence function differently between male and female subjects. 


\section{Regression Analysis}

Although the correlation method is good tool to show the statistical relationship multiple regression analysis has an advantage to predict the amount of contribution accounted by independent variables on dependent variable. In the present study the optimism, gratitude and emotional intelligence were functioning as predictor or independent variable and self-confidence was dependent variable. The observed results are as followed.

Table 3- Showing Predictor of Self-confidence of total subjects as shown by stepwise multiple regression analysis

\begin{tabular}{|c|c|c|c|c|c|c|c|c|c|}
\hline Predictor & $\begin{array}{l}\text { Multip } \\
\text { le }\end{array}$ & $\begin{array}{l}\text { R } \\
\text { Squar } \\
\text { e }\end{array}$ & $\begin{array}{l}\text { Adjuste } \\
\text { d R R } \\
\text { Square }\end{array}$ & $\begin{array}{l}\text { Sted. } \\
\text { Error of } \\
\text { Estimat } \\
\text { e }\end{array}$ & $\begin{array}{l}\text { R } \\
\text { Squar } \\
\text { e } \\
\text { change }\end{array}$ & $\begin{array}{l}\text { F } \\
\text { chang } \\
\text { e }\end{array}$ & $\begin{array}{l}\text { df } \\
1\end{array}$ & $\begin{array}{l}\text { df } \\
2\end{array}$ & $\begin{array}{l}\text { Sig } \\
\text { F }\end{array}$ \\
\hline Optimism & $\begin{array}{l}.240 \\
(9)\end{array}$ & .058 & .053 & $\begin{array}{l}11.8334 \\
8\end{array}$ & .058 & 12.142 & 1 & $\begin{array}{l}19 \\
8\end{array}$ & $\begin{array}{l}.00 \\
1\end{array}$ \\
\hline $\begin{array}{l}\text { Emotional } \\
\text { Intelligence } \\
\text { Optimism }\end{array}$ & $\begin{array}{l}.285 \\
(9)\end{array}$ & .081 & .072 & $\begin{array}{l}11.7153 \\
5\end{array}$ & .023 & 5.013 & 1 & $\begin{array}{l}19 \\
7\end{array}$ & $\begin{array}{l}.02 \\
6\end{array}$ \\
\hline
\end{tabular}

The Table-3 is showing summary of regression analysis indicated that out of three predicator variables only two variables, i.e. optimism and emotional intelligence meet the criteria. The variable optimism as predictor variable contributed a multiple $\mathrm{R}=.240(\mathrm{P}<.01)$ and $\mathrm{R}$ Square is .58. This indicated that about $6 \%$ of self-confidence was accounted by optimism. This means that if 1 unit of optimism is increased $6 \%$ of self-confidence can be predicted. The final significant model emerge as adjusted $\mathrm{R}$ square $=.053(\mathrm{~F}-1,198=12.142 \mathrm{P}>.01)$ for Optimism and selfconfidence.

Further it is obtained that the second predictor variable optimism in association with emotional intelligence as predictor variable commonly contributed a multiple $\mathrm{R}=.285(\mathrm{P}<.01)$ and $\mathrm{R}$ square for this variable $=.081$ and $\mathrm{R}$ Change $=.023$. This indicated that $8 \%$ of variable of self confidence was accounted by optimism \& emotional intelligence together and only $2.3 \%$ of variance of selfconfidence was contributed by emotional intelligence alone. This means that if 1 unit of emotional intelligence increased about $2.3 \%$ of variance of self-confidence can be predicted by Emotional Intelligence along. The final significant model for these variable emerge as adjusted $\mathrm{R}$ square $=.072(\mathrm{~F}-1,197=5.013 \mathrm{P}>.01)$.

Table-4 Predictor of Self-confidence of male subjects as shown by stepwise Multiple Regression Analysis

\begin{tabular}{|l|l|l|l|l|l|l|l|l|l|}
\hline Predictor & $\mathbf{R}$ & $\begin{array}{l}\mathbf{R} \\
\text { Square }\end{array}$ & $\begin{array}{l}\text { Adjusted } \\
\mathbf{R} \\
\text { Square }\end{array}$ & $\begin{array}{l}\text { Sted. } \\
\text { Error of } \\
\text { Estimate }\end{array}$ & $\begin{array}{l}\mathbf{R} \\
\text { Square } \\
\text { change }\end{array}$ & $\begin{array}{l}\mathbf{F} \\
\text { change }\end{array}$ & $\mathbf{d f}_{1}$ & $\mathbf{d f}_{\mathbf{2}}$ & $\begin{array}{l}\text { Sig } \\
\text { F }\end{array}$ \\
\hline Optimism & $.231(9)$ & .053 & .044 & 12.84838 & .053 & 5.515 & 1 & 98 & .021 \\
\hline
\end{tabular}




\section{Optimism, Gratitude and Emotional Intelligence as Correlates of Self-Confidence of Early Adults}

From Table-4, the result indicated that out of the three predictor variables, only optimism was found as predictor variable for self-confidence. The results indicated that optimism contributed a multiple $\mathrm{R}=.231 \quad(\mathrm{P}<.01)$ and $\mathrm{R}$ square for this variable is .053 . This indicated that $5 \%$ of variance of self-confidence is accounted by optimism. This means that if 1 unit of optimism is increased $5 \%$ of self-confidence can be predicted. The final significant model for this variable emerge as adjusted $\mathrm{R}$ square $=.044\left(\mathrm{~F}_{1}, 98-5.515, \mathrm{P}<.01\right)$. This is showing the negative significant relationship with optimism and self-confidence.

\section{DISCUSSION}

\section{Optimism \& Self-Confidence}

From the results it can be obtained that the optimism was found to be significantly and negatively correlated with self confidence in total subjects and gender groups and also found to be the predictor variable for self confidence in total subjects and male subjects. The results were quite interesting and revealed that the two variables co-vary in the opposite manner. The reason may be related to the fact that concept of optimism is related to a person's strength of personality (Pappas, 2010) helping him/her to grow their future and getting success in life with a positive view and expectation of best possible outcome from the situation (Zetlin, 2013). It is a mental attitude or world view that one interprets situations or events as being best. The more optimism one generate, the more possibility one have to not concentrate on the faiths related to needful abilities and skills, because cognition is relying on subjective faith of possible outcome from the situation, which are basically the components of self confidence. In other words, the more optimism one has the more possibility one has to not rely on self confidence (Bilanich, 2009). It can also be said another way that if you have evaluated the situation as a success on the basis of past experiences and possible resource availability in the situation no space left from self confidence, This is the reason that high self confidence never fails but high optimism always remain in doubt in reference to success and pre-decided goal attainment. Therefore, a negative correlation between self-confidence and optimism was found in the result of the present study. The regression analysis model also indicated that optimism negatively function as predictor variable for self-confidence and contributes a little about $6 \%$ of variance to the self-confidence. Although, the contribution is very low but indicated negative influence on self-confidence.

\section{Self-confidence and Gratitude}

Result also indicated a negative correlation between self-confidence and gratitude but it was an insignificant correlation between these variables. The important thing about having gratitude is the quality of the feeling that accompanies it. Gratitude is an emotion that occurs after people receive help depending on how they interpret to situation (Wikipedia, 2015). Results indicated no relationship between self-confidence and gratitude. Thus may be due to the fact of that confident persons may have a feeling of gratitude because they do not need to ask for help and it also not related to self confidence in reference to success and goal attainment. People with high self-confidence trust on their abilities and do not depend on others help. People also not trust one another if they are easily suspicious of one another (Govier, 1997). A confident person will come 
to the relationship as a whole and not in need of confirmation of value from his or her mate (Eanes, 2002). The regression analysis model also indicated that gratitude does not focus to be the criterion variable for self-confidence.

\section{Self-Confidence and Emotional Intelligence}

Although Emotional Intelligence is defined as a person's self-confidence, self- awareness and self- control (Goleman, 1998) and it was also defines as an ability to monitor one's own and other people's emotion (Wikipedia, 2015). It is more important than one's intelligence (IQ) in attaining success in their lives and careers (Akers \& Porter, 2013), but the obtained result indicated that Emotional Intelligence has negative correlation with self-confidence. This means that high emotional intelligence may lead to poor self confidence. This may be because both the factors are the personality traits and function differently in different situations. One is an ability to handle emotions in negative situation where as other is related to a faith in ourselves that we can overcome the adverse situation by our abilities by hook or by crook. So, both may be have a negative relationship due to opposite in nature. Regression analysis model also indicated that self-confidence negatively predicted by if Emotional Intelligence of college going subjects. In other words it can be said that when a person is highly confident he will do anything to win the situation where emotional regulation may be decreased due to aggressive attention toward goal.

\section{CONCLUSION}

So from the above results and its discussion, it can be concluded that the optimism was found to be significantly and negatively correlated with self confidence in total subjects and gender groups and also found to be the predictor variable for self confidence in total subjects and male subjects with a valid reason. Emotional intelligence was found negatively and significantly correlated with self confidence in male subjects but not in female subjects but no significant correlation was found between gratitude and self confidence.

\section{REFERENCES}

Akers, M. \& Porter, G. (2013). What is Emotional Intelligence (EI). Retrieved on June 2013 from www.http://psychcentral.com.

Bilanich, B. (2009). Self-Confidence, Optimism and Success. Retrieved May 12, 2011 from http://www.fastcompany.com.

Cheng, H. \& Furnham, A. (2002). Personality, Peer Relations and Self-Confidence as Predictors of Happiness and Loneliness. Journal \& Adolescence, 25, 327-339.

Cox, R. (2001). Self-Concept of Children and Their Intelligence Achievement Interests and Anxiety. Retrieved May 11, 2011 from www.kon.org.com.

Eanes, J. (2002). What Makes A Self Confident Person Attractive. Retrieved May 12, 2011 From http://www.book.google.co.in.

Emmons, R.A. \& Crumpler, C.A. (2000). Gratitude as a Human Strength. Appraising the Evidence. Journal of Social and Clinical Psychology, 19, 56-69. 
Giacalone, R.A., Paul, K., \& Jurki Cwicz, C.L. (2005). A Preliminary Investigation into The Role \& Positive Psychology in Consumer Sensitivity to Corporate Social Performance, Journal of Business Ethics, 58, 295-305.

Goel, M. \& Aggarwal, P. (2012). A Comparative Study of Self Confidence of Single Child and Child with Sibling, Journal of Research in Social Sciences, 2, 3.

Goleman, D. (1998). Working With Emotional Intelligence, New York, Bantam Books.

Govier, T. (1997). Social Trust and Human Communities, Nontreal and Kingston : McGillQueen's University, Press.

Jones, L. (2001). Self-Concept \& Children and Their Intelligence Achievement Interests and Anxiety. Retrieved May 11, 2011 from http:.// www.kon.org.com.

Kashdan, T.B., Uswatte, G. \& Julina, T. (2006). Gratitude and Hedonic and Eudaimonic Wellbeing in Vietnam War Veterans, Behaviour Research and Therapy, 44(2), 177-199.

Lam, S.K., Schaub, R.J. \& Brown, A.D. (2004). Laboratory and Field Studies \& Group Performance Cognitions. Journals of Organizational Behaviour \& Human Decision Process, 94(2), 86-101.

McCullough, M.E., Emmons, R.A. \& Tsang. J.A. (2002). The Grateful Disposition : A Conceputal and Empirical Topography. Journal of Personality and Social Psychology: 32(1), 112-127.

McCullough, N.E., Emmons, R.A. \& Tsang, J.A. (2004). Gratitude in Intermediate Affective Terrain: Links of Grateful Moods to Individual Difference and Daily Emotional Experience, Journal of Personality and Social Psychology, 86(2), 295-309.

Pappas, S. (2010). Optimism Boosts Immune System. Retrieved June, 2013 from http://ww.livescience,com.

Rajput, S. (2013). A Comparative Study of Emotional Intelligence and Self-Confidence Among the Able and Disabled Students At Secondary School Level in Haryana. International Indexed \& Referred Research Journal, 4,42.

Scheier, N.F. \& Carver, C.S. (1994). Distinguishing Optimism from Neuroticism (and Trait Anxiety, Self-Mastery and Self-esteem) A Re-Evaluation of the Life Orientation Test. Journal of Personality and Social Psychology. 67, 1063-1078.

Watkins, P.C., Schee, J., Ovnicek, N., \& Kotts, R. (2006). The Debt of Gratitude : Dissociating Gratitude and Indebtedness Cognition and Emotion, 20(2), 217-241.

Wikepedia (2015). Gratitude. Retrieved on June, 2013 from http://www.en.wikipedia.org.com.

Zetlin, M. (2013). Train Yourself to be an Optimist: 4 Steps. Retrieved on June, 2013 from http://www.inc.com. 